\title{
An Efficient Cell Selection Approach in 4G Networks
}

\author{
Dr. Abul Bashar \\ Prince Mohammad Bin Fahd University, \\ Kingdom of Saudi Arabia.
}

\begin{abstract}
The cell selection mechanism that provides services to each mobile station is referred to as cell selection. For maximizing the current and future of cellular networks, it is necessary to optimize the process. The OFDMA-based systems are LTE-Advanced and IEEE $802.16 \mathrm{~m}$ for satisfying the mobile station minimum demand by having one or more base station simultaneously. The problem is considered as the optimization problem and defines the problem as it is not considered as NPhard and also not possible for approximation with a reasonable factor. The assumption is that the maximum required bandwidth of a single mobile station is defined as the r-fraction of the capacity of the base station. For cell selection, this paper consists of two algorithms. The first algorithm defines the creation of a (1-r) approximate solution, this is applicable when the coverage of the mobile station is done by one or more base station simultaneously. The second algorithm defines the creation of an approximate solution (1-r /2-r) when the coverage of each mobile station is covered by a maximum one base station. A simulation research that describes the benefit of using our algorithms that have limited and high-loaded power for the future of $4 \mathrm{G}$ networks completes the overall study. The performance and capacity are better than the existing algorithms.
\end{abstract}

Keywords: Cellular Networks, Cell Selection, LTE-Advanced, 4G Networks, Cell Searching

\section{Introduction}

When the connection is wireless, a mobile network or cellular network is described as a communication network which is spread over certain areas known as cells. This is done by having at least one fixed-location transceiver that is referred to as the base station or cell site. In most of the modern cellular systems, it has to provide services cost-effectively. It is important to have installed equipment at the maximum utilization to serve the maximum number of customers more efficiently at a particular time [1]. It defines one main problem that is the cell selection mechanism. This mechanism is used for determining the base station that has to provide service to the particular mobile station. Cell Selection is known as the process that is performed when it enters the network on the mobile station or when the mobile station is moving in idle mode is referred to in HSPA as cell change or cell reselection. This cell selection process is normally performed by a local procedure that is initiated in the current cellular systems by a mobile device. SNR conducts this detection mechanism and the mobile devices calculate the SNR level for many base stations within the same radio range by providing a priority queue that is referred to as the active set for best detection. This will allow the service subscription request to be officially sent sequentially by the order of the queue to the corresponding base stations [2]. To validate the request positively, the procedure is initiated by the mobile station linked to the corresponding first base station. For example, if the microcell A does not have sufficient capacity to meet the demand for MS2 where the heavy data client is considered to be MS2. In that case, the MS1 is served by the picocell B and both the MS1 and MS2 requests are finally fulfilled. There are some reasons for service request rejections are drop call areas or can be handovers. It was happened due to the exhaustion of base station capacity [3]. The main characteristics of the networks are Intelligent Node Association, Relay Support, Resource Allocation, Spectrum aggregation, Self-organizing networks and Beamforming coordination. The cell selection process in the $4 \mathrm{G}$ technology is used for providing efficient service at a low cost. The LTE-Advanced is used as an IMT-Advanced technology to support the establishment and consideration of the LTE and EUTRAN. This technology is also called as LTE release 10 for offering high bitrates and high capacity in a cost-effective way [4]. When the data rate is increased at downloading $3 \mathrm{Gbps} \&$ uploading is at $1.5 \mathrm{Gbps}$, there is an increase in active subscribers simultaneously and the performance is higher with high inefficiency of the spectrum that provides service compatibility and can work with other radio systems. 
Vol.02/ No. 04

Pages: 188-196

https://www.irojournals.com/tcsst/

DOI: https://doi.org/10.36548/jtcsst.2020.4.003

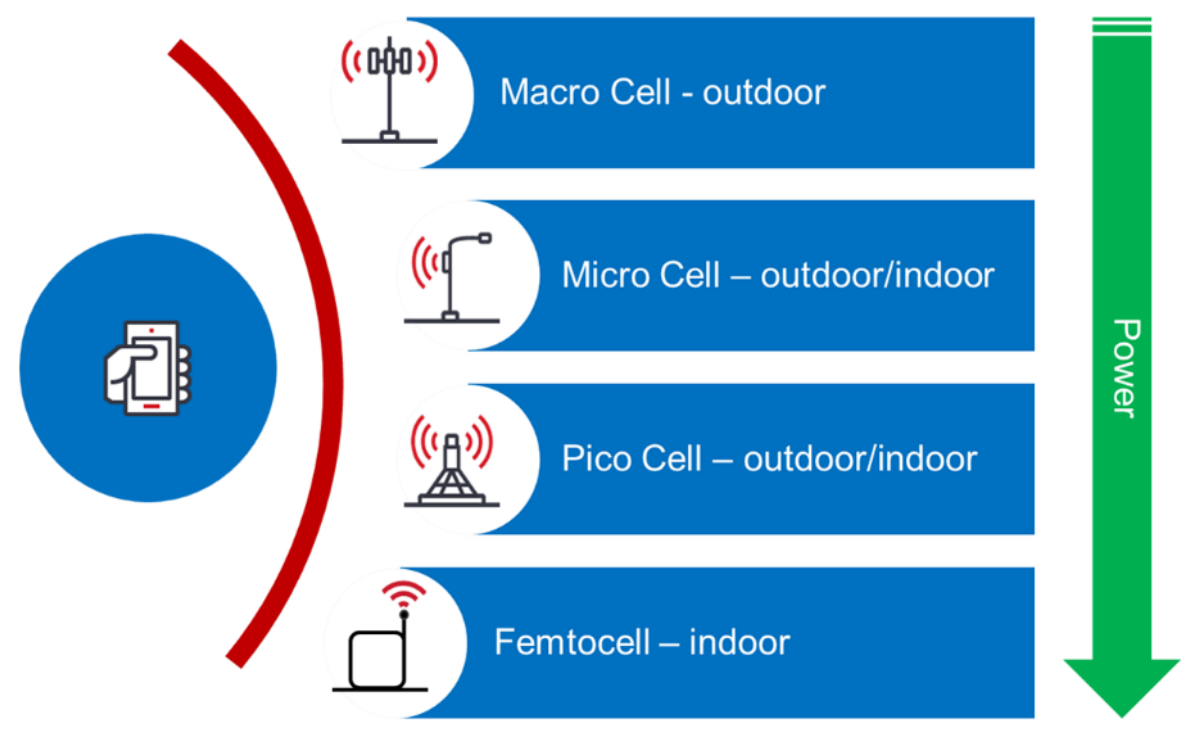

Fig.1 Different types of cells

Every base station is having some area coverage that was designed by the set of clients for an efficient service [5]. In some situation, it is not able to satisfy the demands of all the users of the base stations due to its capacity constraints. Different types of cells are varied from one system to another. The different types of cells are Macrocells, Microcells, Pico cells, Satellite cells and Femtocells [6]. Figure 1 describes the different types of cells. The different generations of networks are 0G, 1G, 2G (EDGE), 3G, 3.5G and 4G (LTE). The 0G cellular generations are also known as a mobile radiotelephone. The main similarity between $1 \mathrm{G}$ and $2 \mathrm{G}$ networks are $1 \mathrm{G}$ is analog and $2 \mathrm{G}$ is digital. The applications of $3 \mathrm{G}$ are mobile internet access, video calls, mobile TV and wireless voice telephony [7]. The $3.5 \mathrm{G}$ is designed for providing better performance than $3 \mathrm{G}$ and some of the capabilities of $4 \mathrm{G}$ technologies are Evolved HSPA and high-speed downlink packet access and 3GPP Long Term Evolution.

\begin{tabular}{|l|l|l|l|l|}
\hline Name & $\begin{array}{l}\text { 1st Generation } \\
\text { Mobile Network }\end{array}$ & $\begin{array}{l}\text { 2nd Generation } \\
\text { Mobile Network }\end{array}$ & $\begin{array}{l}\text { 3rd Generation } \\
\text { Mobile Network }\end{array}$ & $\begin{array}{l}\text { 4th Generation } \\
\text { Mobile Network }\end{array}$ \\
\hline Introduced in year & 1980s & 1993 & 2001 & 2009 \\
\hline Technology & $\begin{array}{l}\text { AMPS (Advanced } \\
\text { Mobile Phone } \\
\text { System), NMT, } \\
\text { TACS }\end{array}$ & IS-95, GSM & $\begin{array}{l}\text { IMT2000, } \\
\text { WCDMA }\end{array}$ & LTE, WiMAX \\
\hline $\begin{array}{l}\text { Multiple Address } \\
\text { /Access system }\end{array}$ & FDMA & TDMA, CDMA & CDMA & CDMA \\
\hline $\begin{array}{l}\text { Speed (data rates) } \\
\text { 2.4 Kbps to } \\
14.4 \text { kbps }\end{array}$ & $\begin{array}{l}14.4 \mathrm{Kbps} \\
\text { First wireless } \\
\text { communication }\end{array}$ & $\begin{array}{l}\text { Digital version of } \\
1 \mathrm{G} \text { technology }\end{array}$ & $\begin{array}{l}\text { Digital broadband, } \\
\text { speed increments }\end{array}$ & $\begin{array}{l}\text { Very high speeds, } \\
\text { All IP }\end{array}$ \\
\hline Features & Voice only & $\begin{array}{l}\text { Multiple users on } \\
\text { single channel }\end{array}$ & $\begin{array}{l}\text { Multimedia } \\
\text { features, Video Call }\end{array}$ & $\begin{array}{l}\text { High Speed, real } \\
\text { time streaming }\end{array}$ \\
\hline Bandwidth & Analog & 25 MHz & $25 \mathrm{MHz}$ & $100 \mathrm{MHz}$ \\
\hline
\end{tabular}

Fig.2 Various Generations of the Networks

Some of the applications of 4G technology are IP telephony, video conferencing, gaming services, cloud computing and mobile web access. The distributed system plays a major role for contributing at least one server for the network and it is considered as the geographically distributed network system that can connect servers from various institutions with the increase in workload. Figure 2 discusses the various generations of the networks. The main features of distributed systems are authentication, distributed virtual file system, authorization or roles and domains and persistent system-wide URL. In authorization, LON-CAPA authorization is role-based. In the 
distributed virtual file system, the LON-CAPA resource pool is considered as one large virtual file system and provides transparent resources replication for providing fast access to the resources [8]. If any resources are available in the system, it is accessed by the system-wide persistent URL. In authentication, the user can enter into any server in the network.

This proposed paper is organized in the following manner: Section I describes the cellular networks. Section II presented the literature survey and section III describes the proposed method. Section IV discusses the results and analysis of the cell selection are presented. In section, $\mathrm{V}$ describes the overall conclusion derived for the proposed approach is stated.

\section{Literature Survey}

The technique for practically extending the Pico cell range by applying the bias value to the power obtained instead of increasing the power transmission at the base station of Pico (PBS). The minimization of the number of UE outages is based on the optimum bias value, such as dividing the radio resource ratios between the PBS and the macro base stations (MBS). It is achieved by the process of trial-and-error [9]. In this paper, using the Qlearning algorithm, the author selects the cell that helps each UE learn to pick and minimize the number of UE outages from the previous methods.

The cell determination method and radio resources are used to provide service to the mobile station by selecting cells and allocating resources (CS-RA). In heterogeneous wireless networks, it explores the CS-RA problem. The proposed work is based on the CS-RA mechanism and it is performed independently by each mobile station. The author formulated two problems such as intra cell-game and inter cell-game. These are based on the selection of best cell depends on the optimal cell selection method [10]. It consists of distributed algorithms for covering independent mobile station coverage, such as the RA and CS-Algorithm.

This paper discusses the neighbor cell search algorithm for LTE/LTE-A system for solving the interference problem for detecting the coherent SSS in the channel estimation of neighbor cell searches and introduces a non-coherent scheme for taking the responsibility of the channel similarity at the adjacent subcarriers [11]. It not only contains SSS and PSS but also combats various carrier frequencies that affects the cell signal of the neighbouring cell and home cell. The proposed algorithm converts the neighbouring cell into a new sequence by removing the synchronization of the home cell for recognition.

The main problem in the wireless cellular system (i.e.,) Femtocell development is inter-cell interference. It is not a simple assignment to coordinate macro-femto inter-cell interference [12]. It needs a minimum connection between the Femto and macro base stations. The author therefore presents the technique of blind intercell interference synchronization in which the Femto base station establishes its own power transmission mechanism and this enables to maintains a constant performance of the cell irrespective of the macro-cell location. This helps us to equalize the macro-degradation.

The author has proposed the cell searching, frequency and time synchronization for the LTE downlink. Many algorithms have compared for the analysis such as cross and reverse correlation and cyclic prefix method based on the cell search feasibility, complexity and performance [13]. It also includes the synchronization process and correct frequency adjustment. Initial coarse estimation does not rely on the residual frequency offset. This provides a great solution for cell searching and LTE synchronization.

In multi-cell systems, cell search uses synchronization signals. This proposed method used to minimize the cross-correlation function magnitude for the and supportable cells for a particular group and maximum value of cross-correlation within the group [14]. This method provides an advantage to the multi-cell environments and gives better performance when it is applied in the heterogeneous cellular network.

Universal frequency reuse is introduced in a hierarchical cellular network and the rate of intra and intercell interference are based on the selection of cells by several overlapping cells for the consumers. An algorithm for cell selection which applies to hierarchical cellular networks has been proposed by the author [15]. The uplink transmission power is regarded as the key parameter in the proposed work and the cells are focused on the collaboration of multiple users instead of a single user. 
As indicated in the LTE standard, the author has proposed the frequency domain synchronization structure and the primary synchronization signal is used in the cell search as a concatenation of the $\mathrm{ZC}$ sequence in the cell search phase 1 . The author then suggested the complex scrambling sequence that does not include the short secondary synchronization signal that is used for cell interference for the cell phase 2 to be descrambled and remapped [16]. For both phase 1 and 2 cell search, they suggested a new frequency domain of PS and SS. It provides better frequency offset and computational complexity over LTE and improves in performance.

In the proposed system, cell identification and the downlink initial synchronization for LTE 3G mobile communication systems that are relied upon the cell-specific pilot symbols and SCH [17]. The proposed method used to improve the performance and supports a huge number of target cells with the use of modulation by cellspecific pilot modulation over two symbols within the particular subframe and guarantees performance based on the cell identification and it is done by mixing the maximum ratio and frequency domain differential crosscorrelation.

\section{Proposed System}

\subsection{Cell Searching in LTE}

When the user wishes to access the LTE cell, the cell must undergo cell searching procedure. It consists of a group of procedures that contains a series of synchronization methods that define UE and some parameters of frequency synchronization that does demodulation of downlink data and it gets transmitted to the uplink slot with the accurate timing and also maintains the user's orthogonality with others [18]. When the user has registered with UE already and one eNodeB. Then the new cell recognition method is taken out of the coverage area, where the related eNodeB allows the UE to find ranges and register new cells. The whole process has now been carried out in the new cell and the range is based on the UE.

\subsection{Procedure of cell searching in the LTE-A}

It comprises a separate cell ID without any reference signal for $\mathrm{SCH}$ recognition. It includes four measures in the LTE-A for implementing cell search.

Step 1: In this stage, by processing the P-SCH symbols, the OFDM symbol timing and carrier frequency offset are established. Cross-correlation and autocorrelation or hybrid detection are used for detecting the frequency offset and timing. This refers to sequences of frequency and time domain synchronization.

Step 2: In this step, the S-SCH symbols are processed using the frequency domain to detect the cell ID group, cell-specific information and frame timing.

Step 3: In this step, one-to-one mapping takes place between $3 \mathrm{P}-\mathrm{SCH}$ sequences and reference signals from the downlink. The specific cell ID is extracted within the cell ID community as in step 2 when using the downlink reference signals.

Step 4: The user can migrate from LTE to LTE advanced with the number of LTE and LTEA terminals with the features of LTE-Advanced for smooth functioning of network migration and can be scheduled by implementing the MBSFN sub frames to LTE release 8 terminals and the operations are combined inside the terminals in the same sub frames themselves and based on the standard reference signal (CRS).

\subsection{LTE-A Cell Selection}

When the mobile device is turned on, it is under many base stations (i.e., eNodeB). If the UE is not surrounded by one of the operators' multiple base stations, but by multiple base stations of different system operators. Even though there are many base stations, the UE fix to only one base station. It also depends on the decision-making process for picking up the particular base station for registering process [19]. Then this process is known as cell selection. The LTE-A network avoids the problem of co-channel interference and the selected cells are used for measuring the cell attributes for satisfying the condition of cell selection.

\section{Methodology}

This method consists of a network with $n * n$ with a grid of client locations and in this, each client has own service request as data or voice. It is defined as 1 and 25 . The number of clients that choose data or voice is $20 \%$. The location is selected for each client was selected randomly over the grid. When the demand is satisfied, it is defined as 1 and the data client is credited with a profit based on the demand. For maintaining the picocells and microcells in the network, it is necessary to implement the AoNDM restricted version. Every client demand must be less than or equal to the base station service capacity $r$-fraction. Picocell capacity is about to be between $0<r<1$ 
with a $25 / \mathrm{r}$ value. The total number of customer specifications for simulating high-load networks is equal to the sum of the capacity of the base station on the network. The ratio between microcells and picocells and the ratio between the corresponding power and radius of microcells and picocells is known to be $\lambda$. When $\lambda$ assumes to some value one can derive the numbers of picocells and microcells [20]. The base station location was randomly selected over the clients as well as grids that are connected with omnidirectional base stations based on each center distance. Based on the analysis, the ratio is taken between the total profit generated from three algorithms and the total profit within the spectrum of all the related customers. It is so difficult to determine the overall profit, so it is easy to consider the cumulative profit of all the related customers as an ideal upper-bound area solution.

\section{Cell Selection by Modified Particle Swarm Optimization (MPSO)}

It is a technique developed from the attributes of social behavior, activating movements and animals communications like birds such as the bat, insects like bees and fishes [20]. The Particle Swarm Optimization is fast when compared to other algorithms like Genetic Algorithm (GA), Ant Colony Optimization and Simulated Annealing (SA).

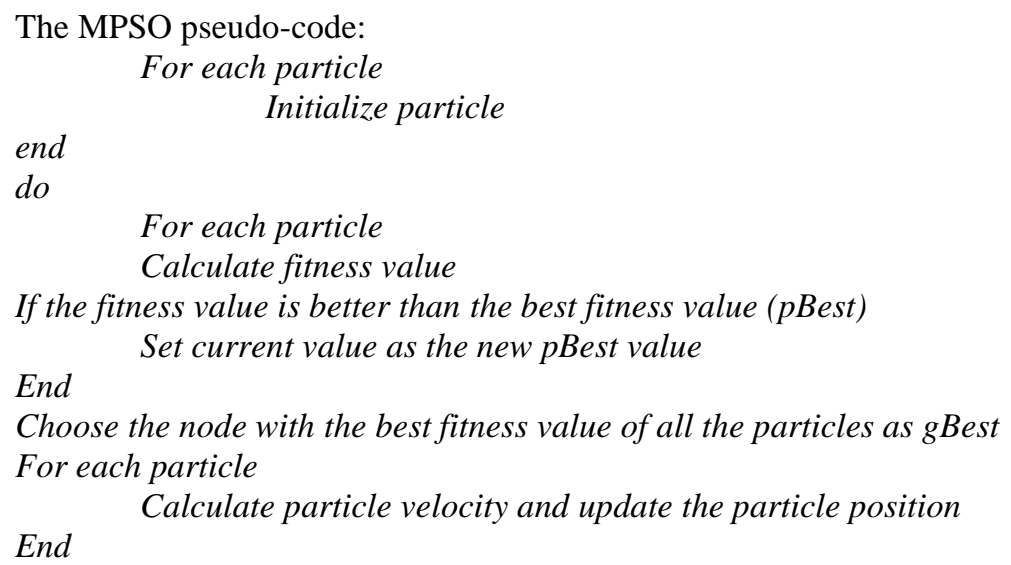

This method is considered as the global and provides guaranteed performance in 4G technology and referred as the standard infrastructure and it is not cost-effective and the coverage is given by WiMAX cells and the cells are overloaded. So, cell selection provides better utilization for coverages.

\subsection{Algorithm framework}

The proposed method consists of two algorithms for the r-AoNDM problem and these algorithms are considered as the local ratio depends on the decomposition profit from every client and it is split into two parts such as one part is proportional to the client demand and other part is remaining profit [21]. This is calculated by a feasible solution and helps to prove that a benefit function is an approximate solution and is proportional to the demand of the customer. This helps to provide the maximal solutions and guarantees with the solution that defines the value is within the factor to derive a feasible solution. The first algorithm has one paradigm covering the cover, where each mobile station is covered by at most one base station [22]. Then the second algorithm is carried out by careful refinement and improvements to the maximum value, and several paradigms cover this and this generates a solution within the factor (1-r) of the optimum solution value given and the polynomial factor increases the complexity.

\section{Results and Analysis}

The primary difference between the present and the proposed algorithm is that the mobile customer's demand is said to be met [23]. A new mechanism for efficient cell selection in $4 \mathrm{G}$ networks was suggested in the proposed process. The proposed algorithm determines that the demand for a mobile station can be satisfied at most by one base station, while the current algorithm meets the demand simultaneously by more than one base station. It satisfies the demand and at least retains and probable coverage at the level of 97 percent by using multiple base stations and also offers 20 percent better coverage than the best method of SNR greedy selection. For getting better performance with the global cell selection algorithms based on current local mobile SNR based protocol. It analyzes through various characteristics like capacity constrained, high-loaded. In most of the geographical areas, all the mobile and base stations are operated at different ranges of frequencies. This leads to the evolution of IEEE 
Journal of trends in Computer Science and Smart technology (TCSST) (2020)

Vol.02/ No. 04

Pages: $188-196$

https://www.irojournals.com/tcsst/

DOI: https://doi.org/10.36548/jtcsst.2020.4.003

802.16m and LTE-A of the mobile station for serving more than one base stations. The three algorithm performance is carried out over various values of $\mathrm{r}$ and network sizes and all the upper, lower and middle curves lead to cover-by many algorithm and nearby one that includes greedy best detected SNR algorithm. It provides better coverage from $5 \%$ to $11 \%$ and improvement is of at least $10 \%$ when compared to the greedy best detected SNR algorithm. It is showed that the performance is of independent of size in the network.

The particular cellular network is chosen simultaneously and it is executed in the system. For selecting the node terminal, the base stations have some frequency range and the output shows the area that contains the mobile and base stations with the range of frequency. It is executed in MATLAB R2011a software.

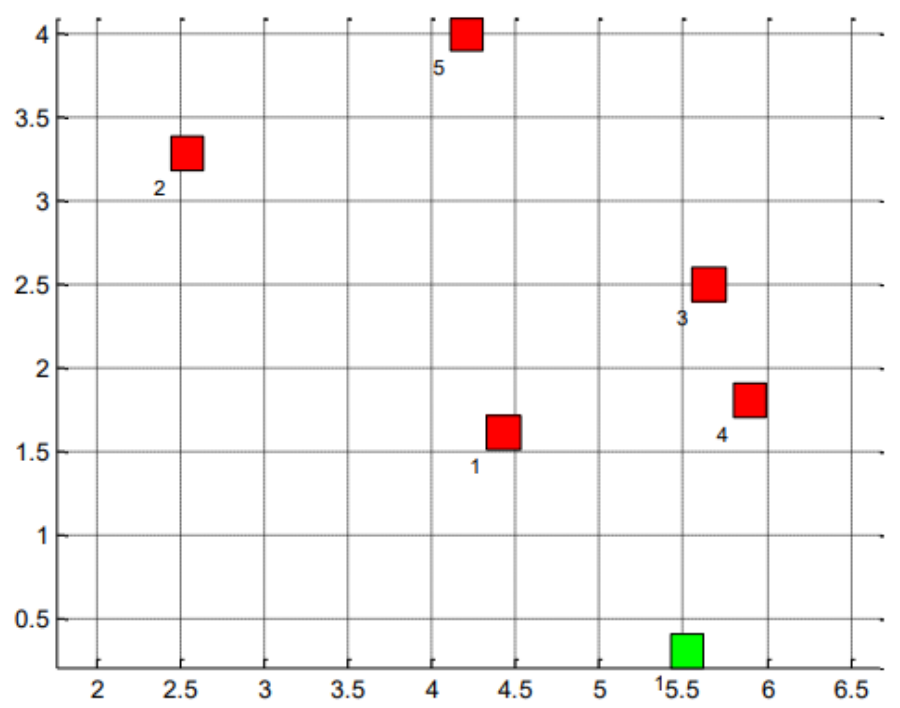

Fig.3 Mobile and Base Stations

The output that shows the mobile and base stations and some colours are available for representing the mobile stations. The mobile station is represented in green colour and each cell is available with some random signal strength values in which they received and it is based on the coverage areas. It can switch over to any cells nearby. Figure 3 represents the mobile and base stations. The geographical area that contains 5 cells with different frequencies and it is changed based on the time and ping pong effect that was carried out in existing method and the distance covered is moderate with all the determined cells.

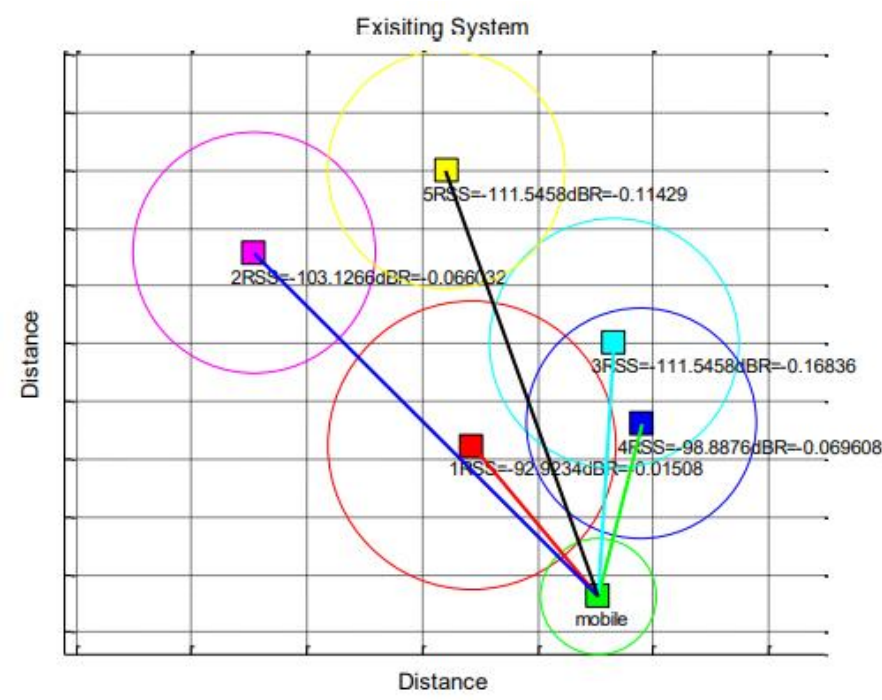

Fig.4 Existing System Connectivity 
Journal of trends in Computer Science and Smart technology (TCSST) (2020)

Vol.02/ No. 04

Pages: 188-196

https://www.irojournals.com/tcsst/

DOI: https://doi.org/10.36548/jtcsst.2020.4.003

This shows the existing output shows more number of base station connectivity and it switches over time. It shows the mobile station choose the cell based on the received signal strength and it varies simultaneously. Figure 4 shows the existing system connectivity in the geographical area. It chooses three cells for better signal quality. The main problem is the ping pong effect where the signal oscillates between the selected cells. It comprises of cost, power and battery are degraded.

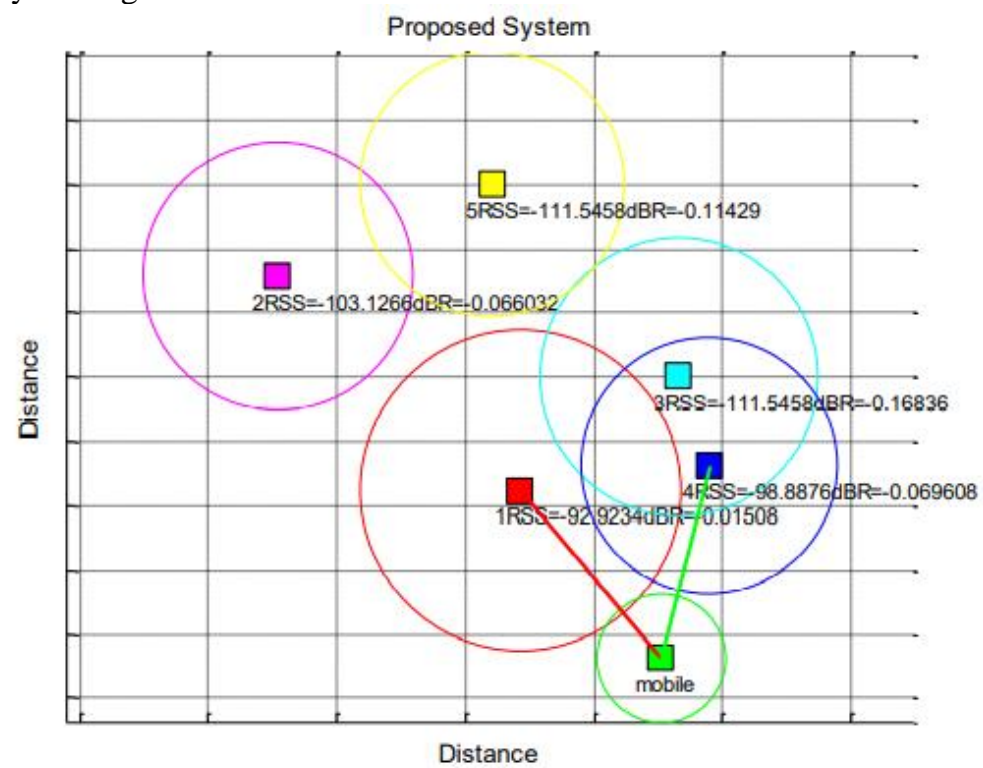

Fig.5 Proposed Cell Selection Connectivity

In the proposed method, $\mathrm{r}$ value is considered as the switching fraction and it is calculated using SNR values and RSS based on the MPSO. Figure 5 shows the proposed method of connectivity. Then the mobile station chooses the best cell depends on the r-value because of this it selects the limited cells than the existing method. In the proposed method, quality of service and resources is maintained.

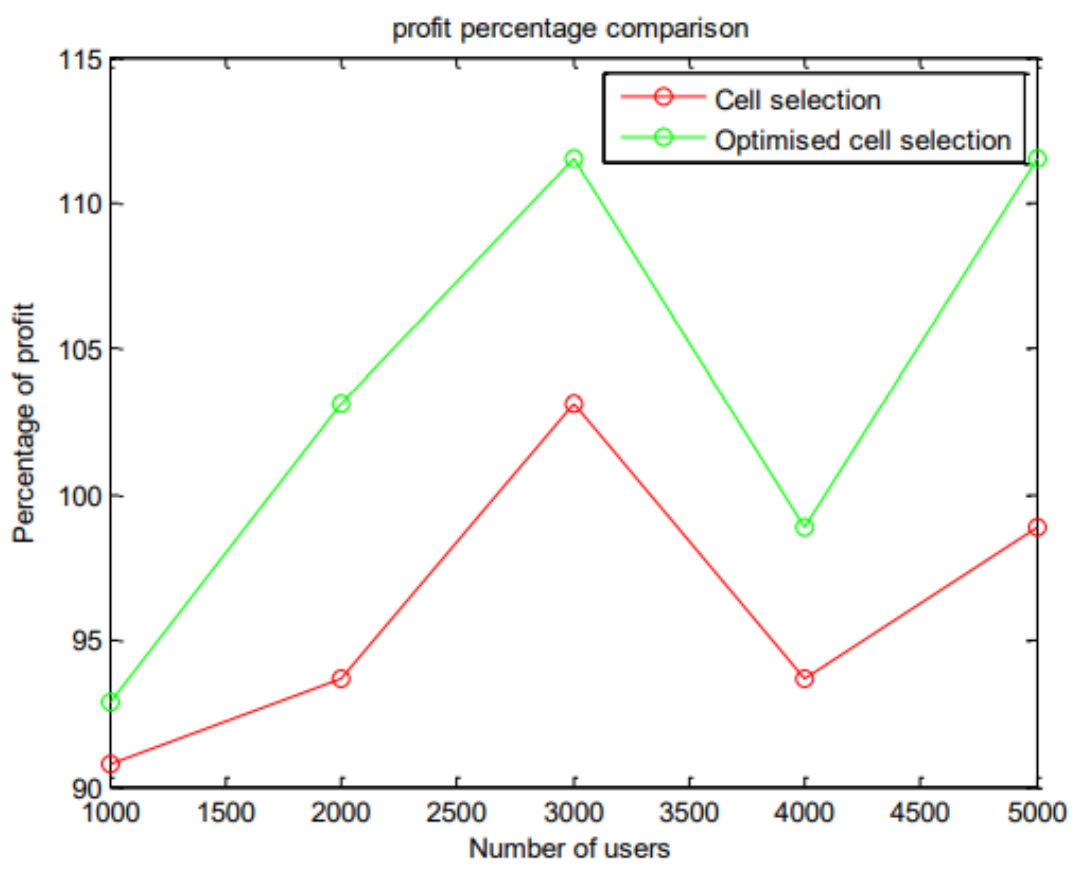

Fig.6 Comparison of Profit Percentage 
Journal of trends in Computer Science and Smart technology (TCSST) (2020)

Vol.02/ No. 04

Pages: 188-196

https://www.irojournals.com/tcsst/

DOI: https://doi.org/10.36548/jtcsst.2020.4.003

The red lines show the cell selection of the existing model and the green line shows the optimized cell selection that is better than the existing model with the number of users with the profit percentage. Figure 4 represents the profit percentage comparison. This figure shows the proposed method efficiency and quality of service is preserved and the resource consumption is limited.

\section{Conclusion}

The proposed algorithm is considered as highly-loaded and capacity-constrained and works $20 \%$ better when compared to existing methods for the future works of $4 \mathrm{G}$ networks. When each customer's demand is marginally greater than the base station capability that contributes to coverage, it is difficult to estimate the instances. The proposed method delivers performance guarantee, global and can address many anticipated 4G technologies.

\section{References}

[1] Amzallag, D., Bar-Yehuda, R., Raz, D., \& Scalosub, G. (2012). Cell selection in 4G cellular networks. IEEE Transactions on mobile computing, 12(7), 1443-1455.

[2] Qu, T., Xiao, D., Yang, D., Jin, W., \& He, Y. (2010, August). Cell selection analysis in outdoor heterogeneous networks. In 2010 3rd International conference on advanced computer theory and engineering (ICACTE) (Vol. 5, pp. V5-554). IEEE.

[3] Ye, Q., Rong, B., Chen, Y., Al-Shalash, M., Caramanis, C., \& Andrews, J. G. (2013). User association for load balancing in heterogeneous cellular networks. IEEE Transactions on Wireless Communications, 12(6), 2706-2716.

[4] Sang, A., Wang, X., Madihian, M., \& Gitlin, R. D. (2004, November). A load-aware handoff and cellsite selection scheme in multi-cell packet data systems. In IEEE Global Telecommunications Conference, 2004. GLOBECOM'04. (Vol. 6, pp. 3931-3936). IEEE.

[5] Patt-Shamir, B., Rawitz, D., \& Scalosub, G. (2012). Distributed approximation of cellular coverage. Journal of Parallel and Distributed Computing, 72(3), 402-408.

[6] Miki, T., Ohya, T., Yoshino, H., \& Umeda, N. (2005, December). The overview of the 4 th generation mobile communication system. In 2005 th International Conference on Information Communications \& Signal Processing (pp. 1600-1604). IEEE.

[7] Mathar, R., \& Schmeink, M. (2002). Integrated optimal cell site selection and frequency allocation for cellular radio networks. Telecommunication Systems, 21(2-4), 339-347.

[8] Hanly, S. V. (1995). An algorithm for combined cell-site selection and power control to maximize cellular spread spectrum capacity. IEEE Journal on selected areas in communications, 13(7), 1332-1340.

[9] Antonopoulos, A., Kartsakli, E., \& Verikoukis, C. (2014). Game theoretic D2D content dissemination in 4G cellular networks. IEEE Communications Magazine, 52(6), 125-132.

[10] Moon, J. M., \& Cho, D. H. (2010). Efficient cell selection algorithm in hierarchical cellular networks: multi-user coordination. IEEE communications letters, 14(2), 157-159.

[11] Cao, Y., Jiang, T., \& Wang, C. (2015). Cooperative device-to-device communications in cellular networks. IEEE wireless communications, 22(3), 124-129.

[12] Amzallag, D., Livschitz, M., Naor, J., \& Raz, D. (2005, November). Cell planning of 4G cellular networks: Algorithmic techniques and results. In 2005 6th IEE International Conference on $3 G$ and Beyond (pp. 1-5). IET.

[13] Barbieri, A., Gaal, P., Geirhofer, S., Ji, T., Malladi, D., Wei, Y., \& Xue, F. (2012, February). Coordinated downlink multi-point communications in heterogeneous cellular networks. In 2012 Information Theory and Applications Workshop (pp. 7-16). IEEE.

[14] Murugadass, A., \& Pachiyappan, A. (2017). Fuzzy logic based coverage and cost effective placement of serving nodes for $4 \mathrm{G}$ and beyond cellular networks. Wireless Communications and Mobile Computing, 2017.

[15] Ghosh, A., Mangalvedhe, N., Ratasuk, R., Mondal, B., Cudak, M., Visotsky, E., ... \& Dhillon, H. S. (2012). Heterogeneous cellular networks: From theory to practice. IEEE communications magazine, 50(6), 54-64.

[16] Qu, T., Xiao, D., \& Yang, D. (2010, October). A novel cell selection method in heterogeneous LTEadvanced systems. In 2010 3rd IEEE International Conference on Broadband Network and Multimedia Technology (IC-BNMT) (pp. 510-513). IEEE.

[17] Song, W., Zhuang, W., \& Cheng, Y. (2007). Load balancing for cellular/WLAN integrated networks. IEEE network, 21(1), 27-33. 
Journal of trends in Computer Science and Smart technology (TCSST) (2020)

Vol.02/ No. 04

Pages: $188-196$

https://www.irojournals.com/tcsst/

DOI: https://doi.org/10.36548/jtcsst.2020.4.003

[18] Choi, Y. J., Lee, K. B., \& Bahk, S. (2007). All-IP 4G network architecture for efficient mobility and resource management. IEEE wireless communications, 14(2), 42-46.

[19] Xu, L., Cheng, X., Liu, Y., Chen, W., Luan, Y., Chao, K., ... \& Xu, B. (2015, October). Mobility load balancing aware radio resource allocation scheme for LTE-advanced cellular networks. In 2015 IEEE 16th international conference on communication technology (ICCT) (pp. 806-812). IEEE.

[20] Wang, S., Zhao, W., \& Wang, C. (2014). Budgeted cell planning for cellular networks with small cells. IEEE Transactions on Vehicular Technology, 64(10), 4797-4806.

[21] Yoshino, M., Shingu, H., Asano, H., Morihiro, Y., \& Okumura, Y. (2019, April). Optimal Cell Selection Method for 5G Heterogeneous Network. In 2019 IEEE 89th Vehicular Technology Conference (VTC2019-Spring) (pp. 1-5). IEEE.

[22] Gao, C., Zhang, H., Liang, Y., \& Hao, P. (2019, September). Performance Evaluation for Uplink Measurement Based Small Cell Selection in User-Centric Networks. In 2019 IEEE 30th Annual International Symposium on Personal, Indoor and Mobile Radio Communications (PIMRC) (pp. 1-6). IEEE.

[23] Avanzato, R., \& Beritelli, F. (2020). Hydrogeological Risk Management in Smart Cities: A New Approach to Rainfall Classification Based on LTE Cell Selection Parameters. IEEE Access, 8, 137161137173. 